\title{
Design-Build-Write: Increasing The Impact Of English For Specific Purposes Learning And Teaching In Aeronautical Engineering Education Through Multiple Intelligences Task Design
}

Dietmar Tatzl, FH JOANNEUM University of Applied Sciences, Austria

\begin{abstract}
This article presents an English for Specific Purposes (ESP) task developed for teaching aeronautical engineering students. The task Design-Build-Write rests on the assumption that engineering students are skilled at mathematical reasoning, problem solving, drawing and constructing. In Gardner's 1983 Multiple Intelligences (MI) theory, these skills strongly correspond to the logical-mathematical, bodily-kinesthetic and spatial intelligences. The current task combines creativity, innovation and problem solving with the description of technical concepts. An enthusiastic learner response in class suggests that the target group of aeronautical engineering students could be engaged and captivated by this assignment.
\end{abstract}

Keywords: Aeronautical Engineering Education; English Language; Technical Description; Design Proposal Abstract; Multiple Intelligences; Higher Education

\section{INTRODUCTION}

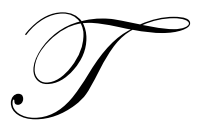

oday, English is the working language of business, science and engineering around the world. The global engineer of the twenty-first century must, therefore, more than ever before, be able to communicate technical content and results in spoken and written form to a variety of audiences. Fluent English language skills have become a constant in practising engineers' profiles of qualifications. This puts a considerable demand on non-native technically gifted learners in higher education settings because they need to compete with English native speakers and other non-native speakers for highly paid positions in industry. Universities around the globe are also challenged because they are faced with an increasing influx of international students whose English-language proficiency levels vary enormously even if they pass the minimum language testing entrance scores required for admission.

As a consequence, English for Specific Purposes (ESP) teaching forms an integral part of the Bachelor and Master of Science in Engineering curricula at the FH JOANNEUM University of Applied Sciences, Graz, Austria. The degree programmes in Aviation also incorporate in total 6 semesters of ESP courses (each course amounting to 30 contact teaching hours per semester) to prepare their aeronautical engineering students for the linguistic requirements of international careers. English for Specific Purposes instruction demands the innovative application of pedagogical theories in order to reach students interested in professional or academic areas other than languages or linguistics. The theory of Multiple Intelligences (MI) formulated in 1983 by Howard Gardner (1983/2004) lends itself well to ESP settings such as aeronautical engineering education because it appreciates the individual strengths and competences of each learner. The present article introduces a task developed for teaching aeronautical engineering students by implementing MI theory in technical language training. The task has been named Design- 
Build-Write $(D B W)$, which reflects both its engineering and linguistic components. Since it employs the idea of multiple intelligences, a short discussion of Gardner's theory follows.

\section{MULTIPLE INTELLIGENCES THEORY AND ITS INTERPRETATION FOR TEACHING}

When Gardner first presented his theory of MI in 1983, he opened new horizons on the perception and understanding of human capabilities. The psychometric tradition of measuring an Intelligence Quotient (IQ) (Becker, 2003; see also Gould, 1981/1992, pp.146-158) has been seriously threatened ever since because MI theory is inclusive rather than exclusive by nature. Gardner's theory acknowledges individual differences and revolves around a balanced view of human strengths and weaknesses. It embraces diversity and intellectual capacity without dogma and replaces the examination-type testing of intelligence by the test of life itself. According to Gardner (1999) in his revised definition, an intelligence is "a biopsychological potential to process information that can be activated in a cultural setting to solve problems or create products that are of value in a culture" (pp. 33-34). Gardner originally introduced seven intelligences but in 1993 added an eighth one, the naturalist intelligence. Table 1 provides a short overview of MI theory.

Table 1: Multiple Intelligences Theory Summarised from Gardner (1999, pp. 41-43, p. 48)

\begin{tabular}{|l|l|l|}
\hline \multicolumn{1}{|c|}{ Intelligence } & \multicolumn{1}{|c|}{ Description } & \multicolumn{1}{|c|}{ Representative Professions } \\
\hline Linguistic & $\begin{array}{l}\text { Sensitivity to linguistic patterns and words; potential to learn } \\
\text { foreign languages with ease; capacity to use spoken and } \\
\text { written language for a distinct purpose }\end{array}$ & Lawyers, speakers, writers, poets \\
\hline Logical-Mathematical & $\begin{array}{l}\text { Analytic skills; capacity to perform mathematical calculations; } \\
\text { potential to investigate and solve problems scientifically }\end{array}$ & Scientists, mathematicians \\
\hline Musical & $\begin{array}{l}\text { Sensitivity to rhythm and sounds; ability to perform, compose } \\
\text { or enjoy musical patterns }\end{array}$ & Musicians, singers \\
\hline Bodily-Kinesthetic & $\begin{array}{l}\text { Capacity to employ one's body or parts of the body for a } \\
\text { certain goal }\end{array}$ & $\begin{array}{l}\text { Dancers, actors, athletes, } \\
\text { craftspersons, surgeons, scientists, } \\
\text { mechanics, engineers }\end{array}$ \\
\hline Spatial & $\begin{array}{l}\text { Sense of orientation; skills in recognising, shaping and making } \\
\text { use of wide and confined space }\end{array}$ & $\begin{array}{l}\text { Navigators, pilots, sculptors, } \\
\text { surgeons, chess players, graphic } \\
\text { artists, architects }\end{array}$ \\
\hline Interpersonal & $\begin{array}{l}\text { Potential to grasp intentions, needs, motivations and wishes of } \\
\text { other people }\end{array}$ & $\begin{array}{l}\text { Salespeople, teachers, clinicians, } \\
\text { religious and political leaders, actors }\end{array}$ \\
\hline Intrapersonal & $\begin{array}{l}\text { Accurate self-perception of one's goals, desires, fears and } \\
\text { abilities }\end{array}$ & No specific professions correlate \\
\hline Naturalist & $\begin{array}{l}\text { Capacity to identify and classify species of the flora and fauna; } \\
\text { skills in creating taxonomies }\end{array}$ & Biologists, scientists \\
\hline
\end{tabular}

MI theory is well founded on "evidence emerging from scientific research, cross-cultural observations, and educational study" (Gardner, 1983/2004, p. 60), and each intelligence is defined by eight criteria from these fields (pp. 63-66). In other terms, an aptitude must meet these criteria in order to qualify as an intelligence:

1. Potential isolation by brain damage

2. Existence of exceptional individuals such as idiot savants and prodigies showing extraordinary abilities in a single domain

3. An identifiable core operation or set of information-processing operations, such as pitch in musical intelligence

4. A distinctive developmental history which may be crowned by high levels of expertise in a domain

5. An evolutionary history and evolutionary plausibility

6. Support from experimental psychological tasks, tests and studies concerning the autonomy of intelligences

7. Support from psychometric findings

8. Embodiment in a symbol system 
In Gardner's theory, all human beings possess the full range of all intelligences but in varying intensities. Indeed, it is the co-occurrence of intelligences that enables a person to perform well in a certain culture: "An individual may not be particularly gifted in any intelligence, and yet, because of a particular combination or blend of skills, he or she may be able to fill some niche uniquely well" (1993/2006, p. 22). In learning, humans also always employ a combination of intelligences, but some of these are more dominant than others and might serve the purpose of teaching (Gardner, 1993/2006, p. 86). Since MI theory is intrinsically linked with human development and learning, it has found much response in educational circles.

A selective reflection of MI theory in educational research should suffice to grasp its potential for English for Specific Purposes instruction. The power of Gardner's theory consists in its pluralisation of the term intelligence to eight different intelligences. MI theory thus rests on an inherent tolerance of the strengths and weaknesses of learners, which fosters a fruitful learning environment. Schmeck and Geisler-Brenstein (1989) underscore the importance of such a framework for learners' progress and suggest that in a "nurturant, flexible, tolerant environment, overall development will proceed of its own accord" (p. 115). The key role of strong intelligences in English as a Foreign Language (EFL) education has already been noted by Chisholm and Beckett (2003), who emphasise their central function "for students to demonstrate learning" (p. 259).

One option for the implementation of MI theory in teaching is to detach the learning scenario from learners' accustomed learning preferences and strong intelligences: "Tasks and activities that do not seem quite as suited to their students' intelligences and style preferences will help them stretch their abilities and styles beyond their ordinary 'comfort zones' and expand their learning and intelligences potentials" (Wu \& Alrabah, 2009, p. 402; cf. Psaltou-Joycey \& Kantaridou, 2011, pp. 109-111). This option is based on the thought that learning takes place when students expand their knowledge of a certain subject by throwing themselves into new challenges.

However, other researchers (Schmeck \& Geisler-Brenstein, 1989, pp. 112-113; Iurea, Neacşu, Safta, \& Suditu, 2011, p. 260; Tulbure, 2011, p. 158) have confirmed the significance of matching teaching methodology to learning preferences because this increases student performance. The same holds true for MI instruction. Hall Haley (2004, p. 171) specifically attests to a better performance of the experimental MI groups compared to the non-MI control groups in her study of foreign language and English as a Second Language (ESL) learners in grades K-12. The rationale behind the current article supports a second option for the implementation of MI theory in teaching. This second option is founded on the thought of employing strong intelligences for improving weaker ones by explicitly connecting tasks and activities to students' preferred intelligences profiles (Millward-Sadler, Casey, Tatzl, 2011, p. 13). As Gündüz and Özcan (2010, p. 9) discovered, engineering students in their sample proved to be more active learners in the sense of hands-on learning compared to students from the educational department. Such findings are also reflected in engineering curricula, which often integrate various projects into their pedagogical approaches. A recent example of integrated Design-Build-Test (DBT) projects is described in Hermon, McCartan and Cunningham (2010). In line with action- and project-oriented engineering education, researchers at the FH JOANNEUM University of Applied Sciences, Graz, Austria detected a multiple intelligences profile of engineering students with the following ranking of the strongest intelligences: (1) interpersonal, (2) bodily-kinesthetic, (3) logical-mathematical, and (4) spatial. As a consequence, then, English as a Foreign Language learning pedagogy should revolve around engineering students' dominant intelligences in order to enhance weaker ones (MillwardSadler et al., 2011, p. 13). The current article introduces a multiple intelligences task developed for students of aeronautical engineering that takes the supposed intelligences preferences of technically oriented learners into full account.

\section{METHODS OF DETECTING TASK IMPACT}

The underlying method for approaching the task experiment under investigation and detecting its impact on learners was action research (Brown \& Rodgers, 2002, pp. 99-100; Burns, 2005). Action research is small-scale practice-oriented research, often only carried out with a single group of students. It consists of a short sequence of steps, from planning to reflection:

Phase I: Develop a plan of action to improve what is already happening.

Phase II: Act to implement the plan. 
Phase III: Observe the effects of action in context[.]

Phase IV: Reflect on these effects[.]

(Kemmis \& McTaggart, 1988, as cited in Brown \& Rodgers, 2002, pp. 99-100)

After designing the task in question, the researcher thus implemented it with a group of students and used immediate classroom observation for detecting its impact on learners. The focus of this observation lay on the behaviour of students, while linguistic impact was perceptible in short texts written in class.

It would be helpful if linguists could measure the language abilities of students with similar precision as engineers and scientists can measure heat or speed. Unfortunately, when investigating languages, researchers are often left with subjective interpretations rather than objective measurements. This may be a reason why qualitative research is rather common in applied linguistics and language teaching. The current article does not rely on statistical evidence or measurement results but on classroom observation and reflection. It is, however, especially the multidisciplinary nature of engineering education in general and aeronautical engineering in particular that also makes multiple research methods acceptable and desirable for advancing the pedagogy in technical fields.

\section{MULTIPLE INTELLIGENCES TASK DESIGN FOR ESP IN AERONAUTICAL ENGINEERING}

The task Design-Build-Write presented here rests on the assumption that engineering students are skilled at mathematical reasoning, problem solving, technical drawing and constructing. These skills strongly correspond to Gardner's logical-mathematical, bodily-kinesthetic and spatial intelligences. The present task pursues the strategy to match instructional methods and materials to engineering students' dominant intelligences for the purpose of English as a Foreign Language learning and teaching (Millward-Sadler et al., 2011, p. 13). This task was specifically developed and implemented for aeronautical engineering students and combines creativity, innovation and problem solving with vocabulary learning and the description of technical concepts. It further engages the core professional engineering tasks of designing and constructing mechanical parts, machines or vehicles and documenting new developments.

Special attention was devoted to task design and preparation. As engineering students tend to be strong in mathematical reasoning, problem solving, drawing and constructing, this task aims at creating a pedagogical environment where students receive the opportunity to combine their technical strengths with practising English as a Foreign Language learning. The task was designed as a hands-on modelling assignment using LEGO ${ }^{\circledR}$ Technic kits. LEGO $^{\circledR}$ products have been used in engineering education before, as in a three-year project relying on programmable LEGO ${ }^{\circledR}$ RCX and LEGO ${ }^{\circledR}$ Mindstorm NXT robots (Adams, Kaczmarczyk, Picton, \& Demian, 2010; see also Enkenberg, 2001, pp. 503-504). The LEGO Group even offers its own website devoted to engineering education in cooperation with the Center for Engineering Educational Outreach, Tufts University (2011). The task described here employs non-programmable LEGO ${ }^{\circledR}$ Technic parts. In the preparation phase, the department's English language instructor ordered nine kits of trucks, cars and helicopters available on the market as well as one large and six small plastic storage boxes. All the LEGO ${ }^{\circledR}$ parts were removed from their original packaging and poured into the large box. It is important that the original construction manuals that come with the kits are not made accessible to learners because those might impede creativity and tempt students to build the original models according to the manuals. The six small plastic boxes were provided for students to transport LEGO ${ }^{\circledR}$ parts from the large storage box to their group tables.

The Design-Build-Write task requires students to model a part, component or assembly they are familiar with from aircraft design with LEGO $^{\circledR}$ Technic and write a corresponding abstract for a design proposal. Its main goal is practising technical spoken interaction and writing skills in a professional engineering setting, while more specific objectives consist in discussing parts, components and assemblies in aeronautical engineering; defining design characteristics and materials; describing operating principles and functions of parts, components and assemblies; and writing an abstract for a design proposal based on students' LEGO ${ }^{\circledR}$ Technic models. This type of task can be characterised as a kinesthetic design, construction and writing task. Its language and skills focus lies on terminology for specifications and materials; explanations of design characteristics; descriptions of the functions of a part, component or assembly; and critical reviewing of design proposal abstracts. The total time reserved for the 
task is 90 minutes, but it may be extended if any of the phases requires more time for students. Table 2 describes the instructions given to students.

Table 2: Instructions Handed out to Students for the Design-Build-Write Task Design-Build-Write: Task and Instructions

A box of LEGO ${ }^{\circledR}$ Technic is provided for this task in class.

Total time: approximately 90 minutes, but may be extended

- Together with a colleague, draft a part, component or assembly used in aeronautical engineering you are familiar with on paper (pairs).

- Build a LEGO ${ }^{\circledR}$ Technic model of your draft (pairs). These two steps should not take more than 40 minutes.

- Define its design characteristics in an abstract and include some specifications for the real part as if it was to be manufactured. Rely on the phrases provided for this purpose (pairs).

- Team up with another pair of students and based on your design proposal abstract explain the operating principle and functions of your part, component or assembly to your colleagues (groups of four).

- The other two students in the group function as critical reviewers of your abstract and should try to find ways of making it even more convincing (groups of four).

After the first two phases of drafting and building their models, students receive another handout containing useful phrases for writing design proposal abstracts (Table 3). Students are supposed to work with these phrases and incorporate some into their abstracts during the in-class writing phase. However, students should also be encouraged to apply their own wording wherever possible in order to develop appropriate and fluent text production specific to topic, situation, genre and task.

Table 3: Handout Containing Useful Phrases for the Writing Phase of the Design-Build-Write Task

\begin{tabular}{|l|}
\hline Useful phrases \\
\hline The project group proposes to design a/an $\ldots$ \\
Its main features are ... \\
Other features of the design include $\ldots$ \\
The proposed $\ldots$ uses the following materials: ... \\
The most critical technology-readiness issue is ... \\
This ... would be the only one of its type, so that ... \\
With this ... the project group enters market competition with ..., but .... \\
Companies such as ... have announced that they ... \\
The main characteristics of the ... are given ... \\
The principal design drivers are ... \\
Manufacturing will require ... because ... \\
Production costs will amount to approximately .... \\
Maintenance will prove ... \\
The predicted product life-cycle ...
\end{tabular}

\section{RESULTS OF THE DESIGN-BUILD-WRITE TASK IN AERONAUTICAL ENGINEERING}

Twenty-seven second-year students at the Department of Aviation completed the multiple intelligences task presented in this article in the seminar English for Aeronautical Technology and Management on May 11, 2011. In the course of a 90-minute session, students drafted and built the following parts, components and assemblies as LEGO $^{\circledR}$ Technic models:

- $\quad$ Sweep-wing control mechanism

- $\quad$ Double-bladed rotor on three-wheeled test vehicle

- Tail rotor of a helicopter

- $\quad$ Retractable hook-up system for space gliders

- Moon robot with retracting landing legs and simultaneous satellite dish extraction

- $\quad$ Flying motorbike with retracting gear 
- Variable pitch propeller on testbed with automated gliding configuration setting in case of engine failure

- Spoiler

- $\quad$ GAU-8 Avenger $30 \mathrm{~mm}$ board cannon

- $\quad$ Elevator

- Throttle-levers of an A380

- $\quad$ Damped front landing gear

- $\quad$ Retractable main landing gear

Students named their models themselves, and only those who built a replica model of an existing machine gun and the throttle levers of an Airbus A380 had slightly misinterpreted the task instructions because in principle their approach made the writing of a design proposal abstract superfluous. Nevertheless, even these components left sufficient room for creative variations, so that the respective student teams could participate in all phases of the task throughout the full session. Taking the time constraint of 40 minutes for the drafting and building phase into consideration, all student teams produced impressive models with moving and fully functional parts. This fact supports the initial assumption that engineering students are skilled at mathematical reasoning, problem solving, drawing and constructing. In other words, the task activated aeronautical engineering students' strong intelligences for the drafting and building phase. Two examples should illustrate the way students completed this task. Figure 1 shows the LEGO ${ }^{\circledR}$ Technic model of a variable pitch propeller on a testbed, and Table 4 contains the corresponding design proposal abstract written by the students in class.

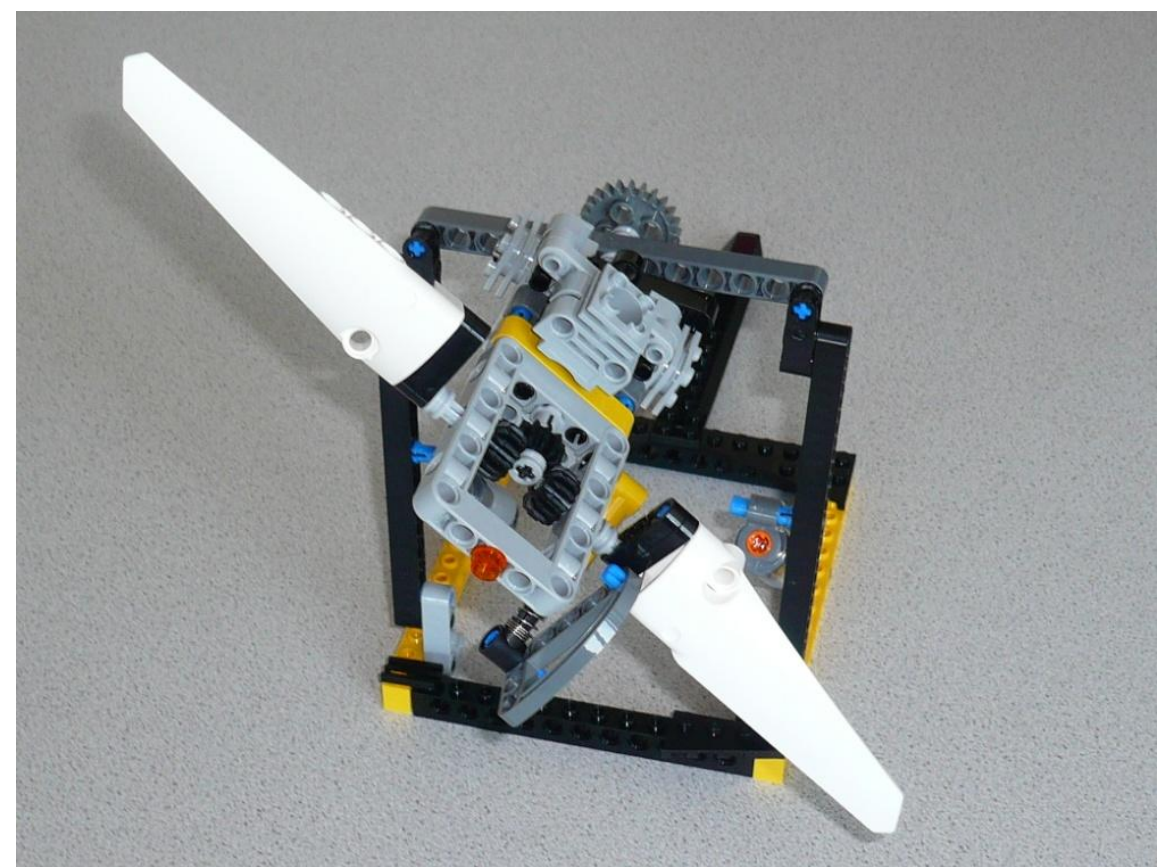

Figure 1: LEGO ${ }^{\circledR}$ Technic Model of a Variable Pitch Propeller on a Testbed

Table 4: Design Proposal Abstract for a Variable Pitch Propeller on a Testbed

The project group, consisting of [names], proposes to design a variable pitch propeller with testbed. Its main features are the variable pitch angle of the rotor blades, which is controlled by a gearwheel system, as well as a testbed, which can change the angle of attack of the airflow. Other features of the design include a piston, which automatically changes the pitch angle the rotor blades in the gliding position, if the engine fails. Mounted in a windtunnel, the variable pitch propeller with its testbed can be used to simulate a wide area of different situations. Therfore, it is a cheap but accurate alternative to other propeller testbeds. This complex but solid proposal will convince possible customers and a high skilled service team will ensure supremacy on the current market. 
Figure 2 and Table 5 depict an aircraft's spoiler built by a different student team.

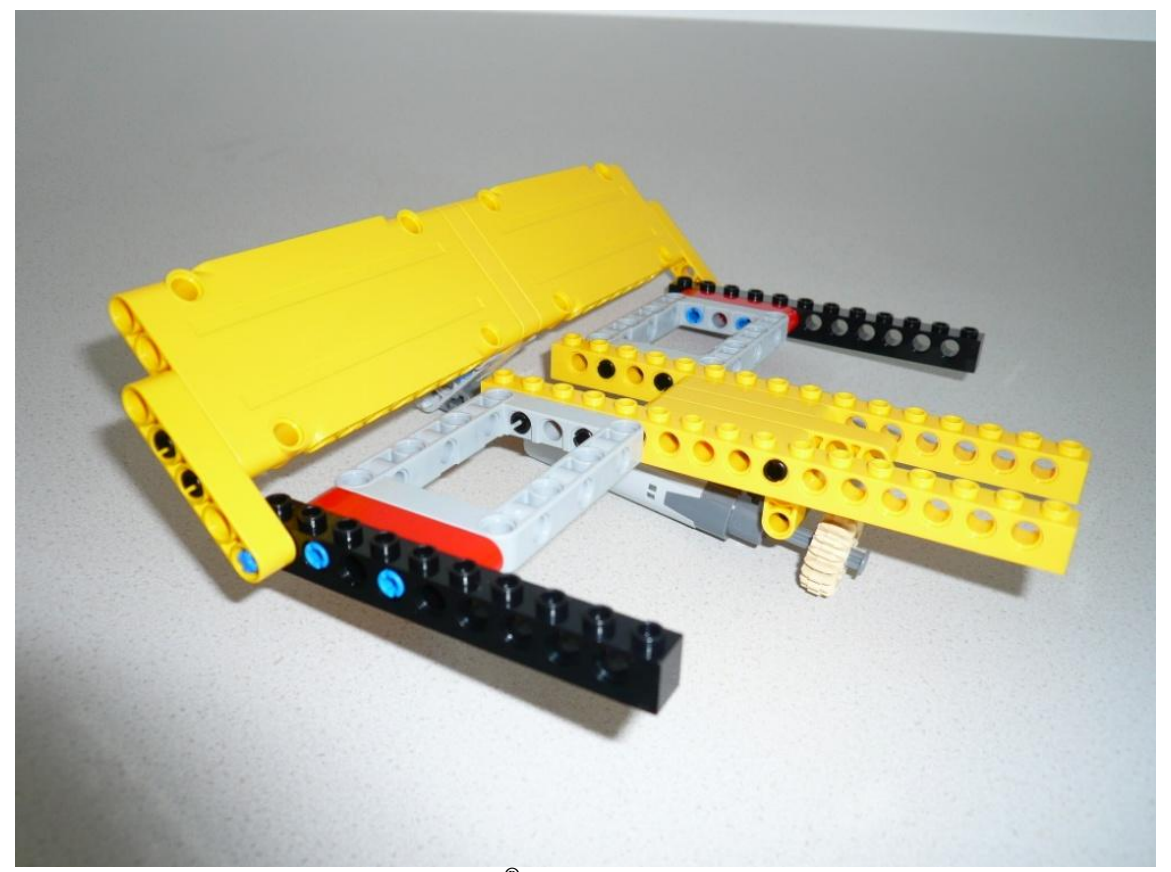

Figure 2: LEGO $^{\circledR}$ Technic Model of a Spoiler

Table 5: Design Proposal Abstract for a Spoiler

The project group proposes to design a spoiler. Its main features are weight, actuator force, area and corrosion protection. Other features of the design include lightning protection. The proposed spoiler uses the following materials: composites, titan and aluminum alloys. Companies such as FACC have announced that they are planning to mass-produce our spoiler design. The principal design driver is the weight. Manufacturing will require an autoclave because of vacuum bag curing. Main part of the production costs is the hand lay up of the composite.

The student abstracts included here have not been corrected and thus show linguistic and content flaws, but they still demonstrate the successful combination of core engineering tasks such as drafting and building models on the one hand and more linguistically oriented tasks such as describing design characteristics, materials, operating principles and functions of parts, components and assemblies on the other. The production of the models laid the foundations for the writing part, and the short texts written by the students provided the basis for the ensuing group discussions. The organisation, content and language of the abstracts reflect the students' linguistic competence at describing technical parts, components and assemblies in the context of a design proposal, even though there is room for improvement in linguistic accuracy, style and focus. Yet the abstracts were written in class by teams of two students each with reciprocal and continuous peer correction during the writing phase, so that the monitoring of linguistic quality formed part of the assignment.

During the group discussion phase of the task, learners explained the operating principles and functions of their designs to their colleagues and critically examined each other's models. This phase met the objectives of practising technical spoken interaction skills. In contrast to written text production in the previous phase, students now moved on to oral technical discussions. Figure 3 captures students involved in the critical review and discussion phase of their models. 


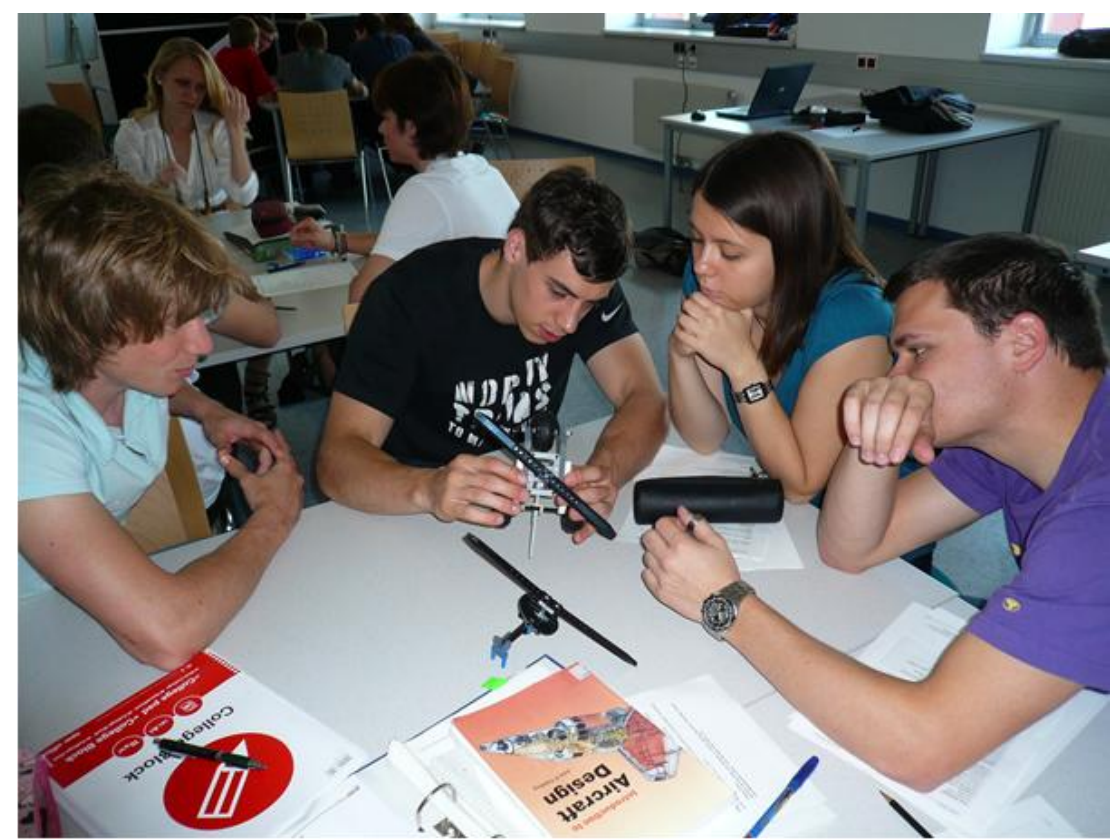

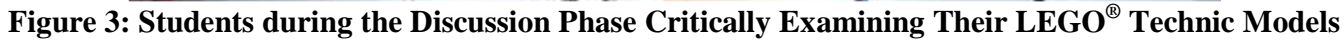

This phase was important for the consolidation of the vocabulary applied in the written abstracts and allowed for an expansion of technical terms by means of listening to explanations, reviewing design approaches and discussing critical issues. Students thus received the opportunity to describe their own models and ask questions or make suggestions about other teams' creations. Since this last phase of the task can be repeated as long as every student design team has matched up with every other team in class, oral practice and student talk time can be increased and the instructor receives additional flexibility concerning the question when to end the activity.

The main intelligence targeted through this task was the linguistic intelligence. By activating core engineering intelligences, hence, students were encouraged to improve and expand their linguistic competences in the areas of technical writing and spoken interaction. Both the abstracts and the group discussions demonstrated that this triggering function of students' strong intelligences works in practice and supports English as a Foreign Language learning in specific settings. The drafting and building phases dominated by engineering skills served the important purpose of employing learners' major interests and aptitudes for improving a less prominent intelligence. By setting tasks that learners feel familiar with, ESP instructors may tune their students into a pedagogical scenario that aims at developing and expanding linguistic competences. This smooth integration of several intelligences with different functions into a single learning task, therefore, can accomplish the development of target skills in an encouraging and supportive environment.

\section{VARIATIONS OF THE DESIGN-BUILD-WRITE TASK IN AERONAUTICAL ENGINEERING}

The original task presented here was conducted within a 90-minute contact teaching unit in class. In order to shift the focus from spoken interaction and team writing to longer writing assignments, however, this task can be easily extended and modified. Students could, for instance, use the 90-minute session described in this article as a starting point for writing full-length individual design proposals for their LEGO ${ }^{\circledR}$ Technic models as a course assignment. These proposals could be submitted to a virtual design contest where a jury consisting of student members from another year group or lecturers might vote for the best design devised. Alternatively, students could use their LEGO ${ }^{\circledR}$ Technic models as a springboard for a research project where they could compare their suggestions with the actual designs of similar parts from industry and literature. As an outcome of the project, they could write a defence of their solutions as opposed to professional engineers' design approaches and present their findings to their 
colleagues and the course instructor. These are only two modifications of the task presented, which lends itself well to further applications in engineering education settings.

\section{DISCUSSION OF TASK IMPACT AND AERONAUTICAL ENGINEERING STUDENTS' REACTIONS}

The impacts and learning outcomes of any single in-class activity are difficult to measure objectively. No such attempt at quantitatively measuring the outcomes of the task experiment under consideration has been undertaken for this reason. In line with the action research method, long-term effects of the task experiment were not investigated. Indeed, for evaluating the practicability of a single task, a longitudinal study might be inefficient, although conducting the assignment with several student groups and comparing its perceived impact across educational levels and over the years could yield interesting insights. Classroom observation, the method chosen for evaluating the task, proved appropriate as regards the teaching experiment's orientation towards practice-directed syllabus advancement.

The linguistic impact of the Design-Build-Write task is perceptible in the two sample abstracts provided above. Students used phrases from the handout distributed in class but also trusted in their own expressions for describing technical components and their functions. Even though the design proposal abstracts are not error free, they still represent clear subject-specific texts that communicate innovative ideas and technical content.

Similarly, the spontaneous reactions of students immediately during and after the task indicated that it accomplished its objectives and managed to motivate, engage and encourage aeronautical engineering students in an English for Specific Purposes setting. Learner responses to the task were enthusiastic and spontaneous expressions of interest, determination and fun. The ESP instructor observed learners working without interruption until the completion of the task. Students maintained their efforts, concentration and attention throughout all phases of the session and stated that they had enjoyed this teaching unit very much. Their request for repeating the task proved that the target group of aeronautical engineering students could be engaged in ESP learning through their prominent engineering skills and competences. These qualitative observations suggest that students perceived an increased learning effect resulting from the Design-Build-Write task discussed in this article. As a consequence, this assignment has become a constant component of the department's ESP syllabus, and it will remain a recurring activity to enhance the communicative skills of engineering students.

\section{CONCLUSION}

The impact of ESP learning and teaching could be increased by means of a multiple intelligences task. The Design-Build-Write task introduced here involved the creation of LEGO ${ }^{\circledR}$ Technic models as the springboard for an abstracts writing part, and the abstracts composed by the students formed the foundations for the ensuing oral discussion rounds. Raised motivation, attention and technical language interaction with peers were the immediate effects produced. The linguistic impact of the task is noticeable in the sample abstracts included in this article. The spontaneous and enthusiastic learner response to this teaching experiment suggests that the target group of aeronautical engineering students could be reached and captivated by the assignment under consideration. Despite the qualitative observation method applied, the multiple intelligences nature of the teaching experiment allows the assumption that the Design-Build-Write task is generally suited to global engineering education. Even though the task introduced in this contribution is tailored to aeronautical engineering students, educators and ESP practitioners active in other fields and disciplines, such as architecture, civil engineering or automotive, mechanical and electrical engineering, will find it useful for their own work as well. This task is relevant to global educational settings because countries like the United States of America and the United Kingdom attract great numbers of overseas and foreign students enrolling in English-speaking university programmes. It thus facilitates the learning of technical English for non-native speakers in higher education. Furthermore, the intellectual strengths of engineers such as mathematical reasoning, problem solving, technical drawing and constructing tend to be similar all over the world, so that this task is suitable for engineering education in many different countries. 


\section{ACKNOWLEDGEMENTS}

I would like to thank the student year group who participated in the task experiment for their commitment to aeronautical engineering and educational improvement.

\section{AUTHOR INFORMATION}

Dietmar Tatzl is a faculty member of the Department of Aviation, FH JOANNEUM University of Applied Sciences, Graz, Austria, where he has taught English for Specific Purposes to aeronautical engineering and aviation management students for nine years. His research interests include English for Science and Technology, Aeronautical English, Engineering Education, Learner Autonomy, Multiple Intelligences and Learner-Centred Instruction. E-mail: dietmar.tatzl@fh-joanneum.at.

\section{REFERENCES}

1. Adams, J., Kaczmarczyk, S., Picton, P., \& Demian, P. (2010). Problem solving and creativity in engineering: Conclusions of a three year project involving reusable learning objects and robots. Engineering Education: Journal of the Higher Education Academy Engineering Subject Centre, 5(2), 4-17. Retrieved on 15 July 2011 from http://www.engsc.ac.uk/journal/index.php/ee/article/view/230/224

2. Becker, K. A. (2003). History of the Stanford-Binet intelligence scales: Content and psychometrics. (Stanford-Binet Intelligence Scales, Fifth Edition Assessment Service Bulletin, No. 1). Itasca, IL: Riverside Publishing.

3. Brown, J. D., \& Rodgers, T. S. (2002). Doing second language research. Oxford Handbooks for Language Teachers. Oxford, UK: Oxford UP.

4. $\quad$ Burns, A. (2005). Action research: An evolving paradigm? Language Teaching, 38, 57-74. doi:10.1017/S0261444805002661

5. Center for Engineering Educational Outreach, Tufts University, \& The LEGO Group. (2011). LEGO ${ }^{\circledR}$ engineering. Accessed on 10 August 2011 at http://www.legoengineering.com/

6. Chisholm, I. M., \& Beckett, E. C. (2003). Teacher preparation for equitable access through the integration of TESOL standards, multiple intelligences and technology. Technology, Pedagogy and Education, 12(2), 249-275.

7. Enkenberg, J. (2001). Instructional design and emerging teaching models in higher education. Computers in Human Behavior, 17(5-6), 495-506. Retrieved on 10 August 2011 from http://www.sciencedirect.com/science/journal/07475632

8. Gardner, H. (1983/2004). Frames of mind: The theory of multiple intelligences (20th anniversary ed.). New York, NY: Basic Books.

9. Gardner, H. (1993/2006). Multiple intelligences: New horizons (rev. ed.). New York, NY: Basic Books.

10. Gardner, H. (1999). Intelligence reframed: Multiple intelligences for the 21st century. New York, NY: Basic Books.

11. Gould, S. J. (1981/1992). The mismeasure of man. London, UK: Penguin.

12. Gündüz, N., \& Özcan, D. (2010). Learning styles of students from different cultures and studying in Near East University. Procedia: Social and Behavioral Sciences, 9, 5-10. Retrieved on 17 March 2011 from http://www.sciencedirect.com/science/journal/18770428; doi:10.1016/j.sbspro.2010.12.107

13. Hall Haley, M. (2004). Learner-centered instruction and the theory of multiple intelligences with second language learners. Teachers College Record, 106(1), 163-180.

14. Hermon, P., McCartan, C., \& Cunningham, G. (2010). Group Design-Build-Test projects as the core of an integrated curriculum in product design and development. Engineering Education: Journal of the Higher Education Academy Engineering Subject Centre, 5(2), 50-58. Retrieved on 15 July 2011 from http://www.engsc.ac.uk/journal/index.php/ee/article/view/234/232

15. Iurea, C., Neaçsu, I., Safta, C. G., \& Suditu, M. (2011). The study of the relation between the teaching methods and the learning styles - The impact upon the students' academic conduct. Procedia: Social and Behavioral Sciences, 11, 256-260. Retrieved on 6 April 2011 from http://www.sciencedirect.com/science/journal/ 18770428; doi:10.1016/j.sbspro.2011.01.072 
16. Millward-Sadler, A., Casey, A., \& Tatzl, D. (2011). A study of engineering students' learning preferences: A multiple intelligences approach. Professional and Academic English, 37(Winter 2010/Spring 2011), 815.

17. Psaltou-Joycey, A., \& Kantaridou, Z. (2011). Major, minor, and negative learning style preferences of university students. System, 39(1), 103-112. Retrieved on 6 April 2011 from http://www.sciencedirect.com/science/journal/0346251X; doi:10.1016/j.system.2011.01.008

18. Schmeck, R. R., \& Geisler-Brenstein, E. (1989). Individual differences that affect the way students approach learning. Learning and Individual Differences, 1(1), 85-124.

19. Tulbure, C. (2011). Do different learning styles require differentiated teaching strategies? Procedia: Social and Behavioral Sciences, 11, 155-159. Retrieved on 6 April 2011 from http://www.sciencedirect.com/science/journal/18770428; doi:10.1016/j.sbspro.2011.01.052

20. Wu, S., \& Alrabah, S. (2009). A cross-cultural study of Taiwanese and Kuwaiti EFL students' learning styles and multiple intelligences. Innovations in Education and Teaching International, 46(4), 393-403. doi:10.1080/14703290903301826 
NOTES 